\title{
CHALMERS
}

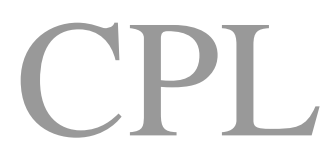

Chalmers Publication Library

Institutional Repository of

Chalmers University of Technology

http://publications.lib.chalmers.se

This is an author produced version of a paper published in Group \& Organization Management.

This paper has been peer-reviewed but does not include the final publisher proof-corrections or journal pagination.

Citation for the published paper:

Bosch-Sijtsema, P. et al.

A framework to Analyze Knowledge Work in Distributed Teams

Group \& Organization Management, 2011, Vol.36, Issue: 3, 275-307] [URL : http://dx.doi.org/10.1177/1059601111403625 ]

Access to the published version may require subscription. Published with permission from:

Sage Publication Inc. 


\section{A FRAMEWORK TO ANALYSE KNOWLEDGE WORK IN DISTRIBUTED TEAMS}

\section{Petra M. Bosch-Sijtsema ${ }^{1}$, Renate Fruchter ${ }^{2}$, Matti Vartiainen $^{3} \&^{3}$}

${ }^{1}$ Chalmers University of Technology, Department of Civil and Environmental Engineering, Construction Management, Sven Hultinsgata 8, SE-412 96 Gothenburg, Sweden, Phone: +46-31-772-1945, Fax: +46-31- 772-1964, Petra.Bosch@ chalmers.se

${ }^{2}$ Stanford University, Civil and Environmental Engineering, Project Based Learning Lab, 473 Via Ortega, Stanford, CA-94305 USA, Phone: +1- 650-725-1549, fax: +1-650-723-4806, Fruchter@stanford.edu

${ }^{3}$ Aalto University School of Science, Department for Industrial Engineering and Management, BIT / Work Psychology and Leadership, P. O. Box 15500, FI-00076 Aalto, Finland, Phone: +358-9-47001, Fax: +358-9-4702-3665, Matti.Vartiainen@tkk.fi/ Virpi.Ruohomaki@tkk.fi

Reference: Bosch-Sijtsema, Petra M., Renate Fruchter, Matti Vartiainen \& Virpi Ruohomäki (2011). A framework to analyze knowledge work in distributed teams. Group \& Organization Management Journal, 36(3), 275 - 307. DOI: 10.1177/1059601111403625 


\section{A FRAMEWORK TO ANALYZE KNOWLEDGE WORK IN}

\section{DISTRIBUTED TEAMS}

This paper presents a framework to analyze knowledge work in the changing context of new ways of working. Knowledge work increasingly takes place as collaboration from different and changing workplaces due to mobility, multi-locational, and geographical distribution of participants. We define the framework based on five key factors that pose challenges to the performance and productivity of knowledge work performed in distributed teams. The framework extends and integrates traditional performance models of task, team structure, and work process, with context factors like workplace, organization policy and ICT infrastructure. The framework is applied in a qualitative comparative cross-case analysis to eight globally distributed teams in two Fortune 100 high-tech companies. We conclude with a series of specific challenges for each factor when studying distributed knowledge work. It is shown that due to changing contexts knowledge workers, teams, and organizations need to constantly adapt, readjust, and re-align according to the five factors.

Keywords: knowledge work, distributed collaboration, task, team structure, team work processes, workplace, organization context.

This paper identifies key factors that impact the performance and productivity of teams of knowledge workers collaborating in distributed and multi-locational work settings. Knowledge work $(\mathrm{KW})$ is defined as the creation, distribution or application of knowledge by highly skilled and autonomous workers using tools and theoretical concepts to produce complex, intangible and tangible results (Antikainen \& Lönnqvist, 2005; Davenport, Thomas \& Cantrell, 2002; Drucker, 1999; Harrison, Wheeler \& Whitehead, 2004; Pyöriä, 2005; Schultze, 2000). We view knowledge as a fluid mix of framed experience, values, contextual information, and expert insight that provides a framework for evaluating and incorporating new experiences (Davenport \& Prusak, 1995). Knowledge workers are defined primarily by the nature of their work, which is relatively unstructured, non-routine, complex and 
situation-specific (Antikainen \& Lönnqvist, 2005; Davenport, Jarvenpaa \& Beers, 1996; Heerwagen, Kampschroer, Powell, \& Loftness, 2004; Scott, 2005). However, in practice, $\mathrm{KW}$ is usually not an individual task, but is performed in cooperation with others working in teams on complex tasks, which individuals cannot perform alone (Han \& Williams, 2008; Pyöriä, 2005).

$\mathrm{KW}$ is increasingly performed in a changing context by team members who are mobile and globally distributed using multiple places and contexts for their work (e.g., BoschSijtsema, Ruohomäki \& Vartiainen, 2009; Lin, 2010). In these settings members can move from one location to the other - multi-location, or are working on a remote location locally, nationally, or globally, we define this as distributed collaboration. In this article we focus on knowledge work that is performed in distributed collaborative teams. Distributed teams are often closely imbedded in a social system having fluid borders with other actors including customers and contingent workers, and often a temporary structure. Furthermore, these teams often work in a project based organization setting, which implies that team members can simultaneously work in multiple projects with different members. Distributed collaboration is closely related to virtual team (VT) literature that studies groups of globally dispersed employees with a common goal carrying out interdependent tasks using mostly technology for communication and collaboration (Armstrong \& Cole, 2002; Bosch-Sijtsema, 2007; Cramton, 2001; Hertel, Geister \& Konradt, 2005; Maznevski \& Chudoba, 2000; Peters \& Karren, 2009). However, VT literature often neglects to discuss the impact of multiple, often changing work locations of these knowledge workers (Vartiainen \& Hyrkkänen, 2010). In this article we identify and study key factors that present specific challenges for $\mathrm{KW}$ performance and productivity in distributed collaboration, such as team task, team structure, team work process, workplace, and organization context.

One of the challenges of $\mathrm{KW}$ is how to improve and value its performance and 
productivity (Antikainen \& Lönnqvist, 2005; Harrison et al., 2004; Drucker, 1991; 1999; Ramírez \& Nembhard, 2004). KW is intangible and often there is no single correct outcome or approach (Orlikowski, 2000). In the new work context of globalization and mobile multilocation supported by technology many traditional approaches to enhance and value $\mathrm{KW}$ outcomes in terms of performance and productivity, i.e., focus on costs as input factors and quantity and timeliness as output factors, might not be suitable. In distributed collaboration, there are many other aspects like work processes between inputs and output and - especially changing contexts that influence the work of knowledge workers (Bosch-Sijtsema et al., 2009). This study defines and applies a framework of five key factors impacting KW in new work contexts, of which we particularly focus on factors that present a challenge for $\mathrm{KW}$ performance and productivity in distributed collaboration. The framework is applied qualitatively in eight case studies at team level focusing on distributed collaboration. Through the framework, we gain insight for each factor to support KW in distributed collaboration.

The structure of the paper is as follows: section two discusses the theoretical points of departure and the five factors of the framework to study $\mathrm{KW}$ in the context of distributed collaboration. In section three the methodology for data gathering and analysis is presented. Section four discusses our main findings in terms of the five factors that impact KW (task, structure, processes, workplace and organization context). In section five we relate the findings to literature, and in section six we conclude the study.

\section{Theoretical points of departure}

Studying the performance and productivity of knowledge work $(\mathrm{KW})$ is an important topic discussed in knowledge work productivity (KWP) literature (Drucker, 1991; 1999). However, the development of measurements for KWP has been difficult and no common measurement categories and methodologies have been accepted (Ramírez \& Nembhard, 
2004). KW is often intangible, complex and there are many different approaches to reach a certain output (Orlikowski, 2000). These characteristics of KW result in difficulties to study KW with traditional productivity methods. Productivity methods are usually based on the ratio of quantitative output and input indicators. However, this simplifies the true nature of $\mathrm{KW}$ as there is not necessarily a direct relation between input and output; there are often intervening and moderating factors related to the process and the context of performing tasks. Moreover, in KW methods of output and input are logically related to intangible factors, e.g., quality of service and increased expertise of employees. The output by input productivity formula alone may not be applicable for $\mathrm{KW}$ and a wider perspective is needed, which would relate 'output' indicators of KW to task, process and contextual factors as 'input' indicators. The majority of KWP methodologies use quantity to assess productivity and only a few apply quality (Ramirez \& Nembhard, 2004) and pay attention to task, process and context factors. Furthermore, $\mathrm{KW}$ is often performed in cooperation with others, who are mobile or globally distributed, which underlines the influence of group structure on productivity.

Since KWP literature mainly focuses on individual KW in collaborative work we address literature focusing on team performance and effectiveness (see reviews of Cohen \& Bailey, 1997; Gladstein, 1984; Guzzo \& Dickson, 1996; Kozlowski \& Ilgen, 2006) that has studied these topics with help of the Input-Process-Output (I-P-O) logic. In this literature, the logic of an input-process-output heuristic has dominated the conceptualization of performance for collocated teams (Antoni \& Hertel, 2009; Kozlowski \& Ilgen, 2006) as well as for VTs (e.g., Hertel et al., 2005; Martins, Gilson, \& Maynard, 2004). In the I-P-O framework (Bell \& Kozlowski, 2002; Kozlowski \& Ilgen, 2006; Marks, Matthieu \& Zacarro, 2001), inputs refer to task characteristics and the composition and structure of the team in terms of the constellation of individual characteristics and resources. Processes refer to activities that team members engage in, combining their resources to resolve task demands. Processes mediate 
the translation of inputs to performance and affective outcomes and learning (Hackman, 1987). As Kozlowski and Ilgen (2006) remark, the I-P-O model is useful as a heuristic model, but treating it as a causal model encourages taking a limited and static perspective on team effectiveness and the dynamic processes that underline it. A team is embedded in a multilevel system of individual, team, and organizational level aspects; which focuses centrally on task-relevant processes; which incorporates temporal dynamics encompassing episodic tasks and developmental progression; and which views team processes and outcomes as emergent phenomena unfolding in a proximal task- or social context that teams in part enact while also being embedded in a larger organization or environmental context (Kozlowski \& Ilgen, 2006; Marks et al., 2001). Even though teams are embedded in larger organization contexts, often the mobile, multi-locational, and distributed locations and changing work contexts are not studied in (virtual) team literature.

An important aspect of knowledge workers is that they often work in many different locations (e.g., home, travelling or commuting, customer's or remote office) (Gareis, Lilischikis \& Mentrup, 2006). The workplace of a distributed worker is an important part that can support individual and collaborative KW (Heerwagen et al., 2004). The constant change in workplace location is particular important to understand in the new work context of mobile and globally distributed work (Halford, 2008). Work related to space in virtual settings often focuses on proximity and distance (O’Leary \& Cummings, 2007; Taylor \& Spicer, 2007). However, current management literature lacks studies of the physical environment and its impact on communication and collaboration (Cairns, 2002; Halford, 2008).

$\mathrm{KW}$ in new work contexts for distributed collaborative teams is not the simple product of individual work, but performance on the team level should also include indicators related to what team members are doing together, how they collaborate, where they work together and how the organization supports their activities. Therefore, understanding KW requires 
understanding of the nature of the team task and identifying factors in collaborative work processes and working environments including the organization context as well as multiple work locations.

\section{Factors impacting distributed knowledge work}

In order to study distributed $\mathrm{KW}$ using different locations we identify five key factors that impose challenges for the performance and productivity of teams working in changing working contexts. In understanding $\mathrm{KW}$ on team level, the performance input-process-output (I-P-O) models are claimed to be incomplete because of minor attention to often transient contextual factors. In the discussed literature, tasks and structural characteristics of distributed teams are considered as input factors determining the nature of intra-team processes, which are then moderated by workplace and organization context factors producing material, behavioural and affective team outcomes. The five factors are task content, team structure, team work process, workplace, and organization context.

1. Task contents in terms of individual and collaborative tasks (Gladstein, 1984; Drucker, 1999; Bell \& Kozlowski, 2002; Kozlowski \& Ilgen, 2006) influences the team structure and collaboration process of teams. In VT literature, the team task sets the minimum requirements for the resource pool needed by team members in terms of knowledge, skills and competences (Bell \& Kozlowski, 2002). Team tasks also determine the workflow structure and coordination demands (i.e., exchanges of information, behavior) necessary for accomplishing individual and team goals and resolving task requirements (Kozlowski \& Ilgen, 2006). Furthermore, in new work contexts many knowledge workers perform multiple tasks and have multiple goals, which increase task complexity (Marks et al., 2001). Both individual and team task contents are combinations of (a) simple to high complexity (Pyöriä, 2005), and can vary from routine to problem-solving and creative tasks (Andriessen, 2003). 
(b) low to high interdependence, and (c) low to high task ambiguity.

Complexity refers to cognitive and emotional demands of tasks, whereas task interdependence describes the degree of task-driven interactions among group members and is determined when team tasks are designed and defined. Task interdependency has been categorized as pooled, sequential, and reciprocal (Thompson, 1967), in which reciprocal interdependency, work requiring mutual adjustment, is common for $\mathrm{KW}$ and project-based teamwork. The higher the task's required level of interdependence and task complexity in distributed settings, the more demanding pacing requirements for intra-team communication and collaboration and for the team's interface with the external context are needed (Bell \& Kozlowski, 2002; Maznevski \& Chodoba, 2000; Thompson, 1967). Task ambiguity is the lack of clarity on colleagues' expectations on the team task. With ambiguous team tasks the time needed to reach a shared goal may increase (Martins et al., 2004).

2. Team structure refers to properties of a team and its members, and consists of team size, members' geographical location, cultural background, temporal boundaries, organizational membership, knowledge, skills, abilities (KSAs), personality characteristics, team tenure (Chi, et al., 2009), and experience that team members bring into the team. These aspects impact performance and effectiveness in teams (Cohen \& Bailey, 1997; Gladstein, 1984; Guzzo \& Dickson, 1996) and are important aspects discussed in VT literature. VT literature discusses expertise, team member's personalities, culture, and language differences in this respect (Hertel et al., 2005; Martins et al., 2004; Maznevski \& Chudoba, 2000). In KWP literature the focus is on autonomy of individual knowledge workers, but teams or team structures that can impact KW are neglected. Autonomy in terms of teams' selfmanaging behavior is positively related to team performance according to literature (Rousseau \& Aubé, 2010).

3. Team work processes are an important factor that has an impact on team performance, 
and affective and behavioral outcomes (Antoni \& Hertel, 2009; Cohen \& Bailey, 1997; Gladstein, 1984; Guzzo \& Dickson, 1996; Marks et al., 2001). Team work processes refer to those interactions with which team members combine their resources to resolve task demands (Antoni \& Hertel, 2009). Team processes are classified according to whether they are cognitive, affective/motivational, or behavioral in nature (Kozlowski \& Ilgen, 2006). This study focuses on the behavioral work processes of coordination, cooperation, and communication of team members; team skills, competencies and performance functions; and regulation, performance dynamics, and adoption. In VTs, the major activities that support team work processes are: (1) planning and goal setting, (2) communication, cooperation, coordination, information transfer and learning, (3) and interpersonal processes like cohesion, trust, and satisfaction (Andriessen 2003; Hertel et al., 2005; Martin et al., 2004, based on Marks et al., 2001). VT literature has strongly focused on communication and the implications of distributed work for trust (Jarvenpaa \& Leidner, 1999), dealing with conflicts (Armstrong \& Cole, 2002) and creation of cohesion (Hertel et al., 2005), while KWP literature studies the planning and goal setting of $\mathrm{KW}$ in terms of timeliness in finalizing work. KWP looks at project success in terms of overall result of the work, as well as team interaction and communication (Ramirez \& Nembhard, 2004).

4. The workplace as a working environment has an impact on the work that is performed (Chan et al., 2007; Heerwagen et al., 2004). A workplace can be perceived as a complex web of interdependent physical, social, and organizational factors that, in combination, influences informal communication, interaction, and learning patterns (Becker, 2002). Right sizing and redesign of space can lead to a better fit between workplace design and users' tasks; employees' workplace can support and improve work performance (Vischer, 2005). In addition, information and communication technology (ICT) is substantially imbedded in workplaces. The connectivity enabled by these technologies has opened new opportunities 
for how, when and where people work. Wherever a workplace of a team member is, it can be seen as an integration of spaces consisting of (1) a physical space (e.g., an office, home or a customer site); (2) a virtual space (i.e., ICT, like email, video conferencing); (3) a social space or interaction space in which people meet formally and informally (e.g., in meeting rooms, coffee rooms, hall ways) (Fruchter, 2005; Vartiainen \& Hyrkkänen, 2010). The virtual space and social space are important for distributed collaboration (Davenport, Thomas \& Cantrell, 2002; Scott 2005). Some studies on global teams show that non-jobrelated communication contents are positively related to performance, satisfaction, and the work climate (Hertel, Geister \& Konradt, 2005). Even though the workplace is important for VTs, it is neglected in current literature on KW.

5. The organization context in which $\mathrm{KW}$ is performed is important to team outcomes (Cohen \& Bailey, 1997). Teams are embedded in a broader organizational system and task environment that drives the difficulty, complexity, and tempo of the team task (Kozlowski \& Ilgen, 2006). This context can be the organizational structure and resources available in the organization (Gladstein, 1984), organizational culture (Moon, 2010), as well as policies concerning ICT infrastructure standards and working conditions. The organization context is mentioned in team performance, VT, and in KWP literature, but often not studied from a multi-location context perspective. In workplace literature the organization context is discussed in terms of infrastructure and policies that have an impact on how people work (Richert \& Rush, 2005), but usually focuses on single locations.

Figure 1 presents the five-factor framework for analysing $\mathrm{KW}$ in distributed work contexts.

Insert Figure 1 about here 
The literature discussed above suggests that task, team structure, team work process, workplace, and organization context factors can impact $\mathrm{KW}$ in new work contexts of distributed collaboration. In the next part of the article we apply these five factors to study qualitatively how they impact KW in globally distributed collaboration.

\section{Methodology}

We performed a comparative in-depth qualitative case study analysis (Eisenhardt, 1989) to identify criteria, based on five factors impacting $\mathrm{KW}$ of distributed collaborative teams. As shown from the discussion above, KW and KW outcomes are difficult to study (Ramírez \& Nembhard, 2004). KW can often only be observed once it is instantiated in human action or information flow (Schultze, 2000). Therefore, we chose to apply an explorative multi-method qualitative approach to study $\mathrm{KW}$ in eight case studies. The studied distributed teams work with both collocated and remote team members and at least one of the team members is working from afar. In Table 1 we present the case studies and apply the categories of O'Leary and Cummings (2007) to describe the different types of dispersion (spatial, temporal and configuration of the team in terms of site, isolation and imbalance) within these distributed teams. In all eight cases we performed observations on how people work when they collaborate in new work contexts. In addition, we collected data using interviews and qualitative surveys.

\section{Case studies}

We studied eight distributed teams in two Fortune-100 high-tech companies. The global companies had a strong emphasis on new product and service design producing consumer electronic products by a high number of academic and professional staff (Baruch, 1997). We studied five teams at one location in the US (PROTO), two teams at Nordic European locations (SERVICE and PERFORM) and one global team in both a US and Nordic 
European location (DESIGN). All teams had different expertise, tasks and workplaces (see Table 1).

\section{INSERT TABLE 1 ABOUT HERE}

Three teams worked in areas like customer relation management (SERVICE), procurement (PROTO PROCURE) and performance management (PERFORM). While four other teams delivered (rapid) prototypes, designs and products (PROTO ENGINEER 1 \& 2, and DESIGN), and tested these prototypes (PROTO TECH). The PROTO MANGEMENT team managed all the five teams of PROTO (see table 1 for more details).

\section{Data collection and analysis}

In this qualitative study, we held semi-structured 11/2-hour interviews with a sample of members (in total 35 interviews) from the eight teams. We applied the same interview outline in all cases. The interviews included topics like: tasks, team and reporting structure, performance, reward system, enablers and hindrances for KW, communication, technology, and workplace issues. With 35 interviews we reached saturation of data (Corbin \& Strauss, 2008). The interviews helped to identify persons we could shadow. We observed and shadowed knowledge workers in their natural (physical) work setting (McDonald, 2005) to understand how they work and collaborate in and from their workplace with their distributed team members. Observations can provide unique insights into the day-to-day working practices because of its emphasis on the direct study of contextualized actions (McDonald, 2005). We observed the workplace of knowledge workers in all eight teams - 2-day observation per team. Furthermore, in total we observed 16 team meetings (both formal and informal) and team teleconference meetings, and we shadowed in total 22 persons for either a 
full or a half-day. For the observations and shadowing we applied observation protocols for different activities. For meetings and individual shadowing we observed the tasks at hand (what), collaboration (what, how, with whom, where), location and layout, and tools and technology used. We collected photographs and video material during our observations, which were used to analyze the observation data. Furthermore, the teams filled out three background surveys developed for this research. Survey 1 collected descriptive data with open-ended questions on the team, individual and collaborative work tasks and the locations these tasks are performed, communication tools used, and perceived enablers and hindrances of KW. Survey 2 included questions on task complexity, interdependence, autonomy, satisfaction, workload, and perceived individual and team performance. Survey 3 focused on the workplace (i.e., reasons for coming to the office, its suitability to individual and collaborative work, and enablers and hindrances), and access to ICT for these teams to perform their work. Next to open-ended questions, other responses were given on 5-point scales from $1=$ low / strongly disagree / not at all to $5=$ high / strongly agree /very much. The survey was sent to all eight teams $(\mathrm{N}=83)$, participating voluntarily, by email and the response rate of all surveys was high from 60 till 100\% (see Baruch \& Holtom, 2008) in all teams (see Table 2). In all teams the team leader or senior manager supported the study, send out the survey invitation, and promoted the study internally. During our data collection we had close communication with the teams and their managers in order to receive their full participation for observations, survey responses and interviews.

\section{INSERT TABLE 2 ABOUT HERE}

Since the survey data was mainly qualitative we only use the survey data qualitatively to validate our field observation findings. The qualitative survey data and the interviews helped 
to select the observation points and people to be shadowed. The cross-case analysis started by coding the open-ended questions of the surveys and interviews performed by the entire team over a period of six months. The team started with a set of top-level themes as initial starting codes defined by the team based on the literature review of the five factors, KW, and measurements of performance. In the next stage individual team members separately continued to code the data and these codes were compared within the team iteratively. The codes were very similar and no large discrepancies between the codes were found. All the qualitative data was systematically put through stages of naming data, comparing data incidents and memoing (Corbin \& Strauss, 2008). Our research team consisted of researchers from organization behavior, VT, and workplace fields and we had the advantage of these three perspectives in analyzing the data. The observational data was in notes, photographs, video and paths drawn on office layouts, and three collocated researchers performed the analysis of the observations over a period of three months. Within the team we developed a protocol of specific themes that were found during the coding process and these themes were confirmed, falsified or explained in more detail with help of the observations.

In order to see if the five factors for KW in distributed settings work well as an analysis framework, we apply the framework in eight case studies. Through analysis and comparison of the multiple data sources we gained more insights related to specific findings as well as validated these findings. All results were reported to the management teams of the eight cases through interactive workshop sessions to validate the findings.

\section{Findings}

We present the findings of the comparative case study analysis by applying the framework to collaborative distributed KW. We focus on key challenges for distributed KW in relation to the five factors of task, team structure, team work processes, workplace, and 
organization context.

\section{High complexity, interdependency, and ambiguity of tasks influence KW}

Although the eight cases had rather different tasks (see Table 1), all team members performed complex and interdependent KW. All teams mentioned that they spend on average $50 \%$ on individual tasks and $50 \%$ on collaborative tasks.

In all cases team members perceived their tasks as very complex. These tasks included creating new ideas (DESIGN), developing prototypes (DESIGN, PROTO ENGINEER1 and ENGINEER2, PROTO TECH), developing new services for their customers (SERVICE), or negotiations and problem solving (PROTO MANAGEMENT, PROTO PROCURE). A manager of DESIGN stated: “Our team's task is to think disruptively for the next 15 years, visionary." The tasks of PERFORM focused mainly on coordination and performance measurement and were perceived as less complex.

Task interdependence was reciprocal, and consequently had a high level of complexity in all cases, and required to be performed by several members simultaneously. The high task interdependence implied that frequent information had to flow between the different remote groups. The teams crossing temporal and spatial boundaries like DESIGN, PROTO ENGINEER1, ENGINEER2, SERVICE, and PERFORM mentioned the challenges of high task interdependence over time. In DESIGN team members sometimes changed their working day hours to night hours in order to be able to work together on projects with team members in the US, Japan, and Europe.

Task ambiguity can be related to project stages and work in geographically distributed teams. We observed that collocated employees, i.e., the five PROTO and PERFORM teams had less task ambiguity than distributed employees, because their collocation offered opportunities to have frequent face-to-face communication to discuss expectations on the 
team tasks. These teams shared the same work environment and context that made their work transparent. However, for the distributed teams like DESIGN and SERVICE task ambiguity was high since they communicated less frequently, had fewer opportunities to discuss mutual expectations due to temporal and spatial distance, and did not share the same work environment.

\section{Asymmetry in team structure configurations influence team performance}

The team structure is applied as an input factor that together with the task, workplace, and organization context influences team work processes, and work outcomes. For team structure we looked into data concerning geographical distribution, function, years of experience, years at the company, and education. Team members mentioned, during the interviews and observations, the importance of the team spirit and opportunity to collaborate with competent, motivated colleagues for their job satisfaction. All the teams mentioned a high level of team satisfaction in terms of their team communication flow, motivation, conflict resolution, and team spirit.

One important aspect in the distributed collaboration context was that most teams had an asymmetric distribution in either skill or experience diversities or in their team configuration. The PROTO cases worked with asymmetric team configurations in which a large part of the team was collocated and some isolated members worked as remote sattelites. One remote member mentioned: "I work remotely from the rest of the team, so I often feel disconnected and must make extra efforts to remain plugged in". The SERVICE and DESIGN cases worked on different sites either in Europe (SERVICE) or globally (DESIGN) and faced spatial, temporal (DESIGN) and configuration distance issues (see table 1). Both cases had isolated team members working remotely as well as an asymmetric team configuration at one of the sites. SERVICE had a group of four managers collocated, while four other managers 
flew in monthly. Furtheremore, the DESIGN team faced an asymmetry not only in spatial configuration but also in the location where most expertise was situated within the team. The larger part of the DESIGN team was collocated in US team and had worked together for 15 years, while the Nordic part of the DESIGN team had only four junior members who had only worked for one to two years for the company. The Nordic team manager mentioned: "We have a very junior team compared to the experienced US team. I see a clear disparity visibly and mentally in the development of the team in the Nordic site compared to the US site."

We considered distribution of seniority, domain expertise, and years of work experience in the company as criteria that influence the performance of a distributed team. An asymmetry in team configuration as a function of these three criteria was perceived as a hindrance to complete remote work (e.g., SERVICE and DESIGN).

\section{Lack of time and access to resources impact work processes}

The work processes of the teams were different. We focused especially on factors that impact team work processes for distributed collaboration.

An important issue emphasized by all cases was that the team members had little access to past corporate knowledge on earlier project tasks. Especially the five PROTO teams and PERFORM viewed this as problematic since work was performed double and could be more effective with access to past knowledge on similar projects or work. We observed in DESIGN that the process of developing ideas (including brainstorm sessions, earlier ideas, failed ideas, etc) was not stored digitally and therefore not shared with the remote members or with other teams within the company. The ability to follow past projects or to learn from work processes at remote sites becomes more difficult when work development processes are not stored or shared. 
All teams mentioned high workloads due to working in multiple projects simultaneously, not having enough time to perform their tasks, and very little reflection time for their complex tasks. Especially in the PROTO teams, members worked on average on six different projects, while some of the PROTO teams, i.e., PROTO MANAGEMENT and ENGINEER2, worked on nine projects simultaneously. On average three of these projects were together with remote sites either in the US, EU and Asia. The workload and multiple project work was perceived to have a negative impact on the work that needed to be done. One team member of PROTO mentioned: "The most current challenge is the enormous amount of information flow that changes daily. The question is how effectively can you keep up with it and meet your performance objectives". SERVICE and PROTO ENGINEER2, and PROTO TECH felt that they had little control over the amount of work they performed. The teams reported in the survey and interviews that they felt a high work and information load and had too little time to perform their task. From observations we noticed that members needed to switch back and forth between different projects and teams daily and this caused an attention load, especially when these teams were geographically distributed.

These high workloads determined high demands on reflection time in order to process the complex work, load of information and dealing with switching attention between projects and teams. However, reflection time was very low in all cases. In six cases i.e., SERVICE and all five PROTOs, team members mentioned that they had no to very little reflection time. In open questions of the survey and interviews, members mentioned they would prefer time to conduct quiet work. Others mention interruptions and workflows that are broken down that impact their work, as well as the fact that they do not have enough time to concentrate and get on with their work. The teams suffered from high workloads, multi-projecting and had to perform ambiguous, complex and interdependent tasks in a distributed global setting. A PROTO member mentioned: "People I need to interact with are unavailable because of 
meetings and their high workload". With little reflection time in their working days, the work becomes taxing on the team members and can impact the outcome and quality of the KW performed.

\section{Impact of physical, virtual, and social workplace}

We primarily analyzed the workplaces from the perspective of the main workplace that is the 'main office' although the team members used other sites for work too. In all cases, the teams reported that their physical workplace - the office - was important to their work. The main reasons for coming to the office were to work with colleagues ( $>60 \%$ of all teams), to interact informally ( $>50 \%$ for seven teams) with colleagues, and to build team identity (seven teams scored $>40 \%$ ). For the teams that developed products and prototypes, another reason for coming to the office was to work in the labs using the prototyping equipment. Below we discuss the physical, virtual, and social workplace in more detail.

Physical workplace. The physical work environments of the teams differed substantially. The two Nordic teams SERVICE and PERFORM worked in open plan offices that offered different types of workspaces for both individual and collaborative tasks, e.g., dedicated desks, team rooms, meeting rooms, free address desks and informal work areas. DESIGN and all PROTO teams worked in older offices with cubicles (with high and low partitions), lab spaces and model workshops. All teams worked with dedicated desks, except SERVICE.

SERVICE members worked in multiple locations both in one office and in four EU countries, the remote EU members of the team traveled to the Nordic office once per month for one week. During their visits to the office, the mobile team members had to occupy a free desk that was available on a first come first served basis and consequently they had to search for available workplaces. One SERVICE member discussed the Nordic office when the team met once a month: "The team members are distributed in three places (places in the same 
building); we have problems to find them when needed, and we have to walk around or call or send an e-mail. Face-to-face communication is decreased." Observed hindrances were related to noise and distractions in the open office workplace and difficulties to locate people of the team due to free address workplaces $-50 \%$ of SERVICE reported noise as a hindrance in the background survey.

For all the PROTO teams, the workplace consisted of a large cubicle land in which the testing and prototyping labs were embedded in the cubicle area. The teams of ENGINEER1/2 and TECH mentioned the advantage of having the labs close by as well as their access to the equipment. However, 20\% of PROTO teams mentioned in the background survey that noise and distractions of the labs were a hindrance for concentrated work. PROTO teams mentioned the difficulty of developing prototypes in a distributed setting. "Team members that are not within a relatively small radius (200 feet) do not have the benefit of informal brainstorming and troubleshooting. Those offsite are left out of many of the important verbal interactions and interactions around hardware or other development and test equipment."

In DESIGN, the team worked in an open office space (dedicated team space) in which the local teams (both in the US and in the Nordic site) were sitting close together and had the ability to share their work on large display walls. $25 \%$ of DESIGN mentioned in the background survey, that the US office space was not suitable for working with their remote team members due to lack of privacy, they perceived noise of the open space, and lack of small meeting rooms in which members could share video and material and prototypes. $19 \%$ of DESIGN mentioned that they perceived difficulty in sharing the material on the large display walls. The US DESIGN team also had remote labs (two miles away) to develop their prototypes. Especially the manager of the US site complained that communication and collaboration was impacted negatively by the remote and multiple locations - $13 \%$ of DESIGN mentioned this in the background survey. 
In PERFORM, the team worked on dedicated desks and used team rooms for team meetings. PERFORM perceived noise and distractions as hindrances of their open plan office $-48 \%$ of PERFORM mentioned this in the background survey.

The data shows in all eight cases that workplace enablers were related to the proximity to team members and their workspaces that allow quick transitions from private dedicated desks to teamwork spaces and labs. A team member of PERFORM mentioned: "In the office, I like the open feeling and interaction. It is easy to see who is present and go to talk with colleagues when needed". However, negative aspects mentioned by PERFORM and SERVICE members were noise and distractions in the office and lack of privacy that decreases concentration and the ability to focus on individual $\mathrm{KW}$ tasks.

Virtual workplace. The virtual workplace consists of communication and collaboration technologies used by the team. SERVICE and PERFORM both mention the access to tools, equipment and ICT infrastructure as an enabler. DESIGN and PROTO teams view the access to tools, software, and equipment as beneficial. However, they feel that the ICT infrastructure does not support remote work. Availability and knowledgeable use of appropriate ICT were relevant enablers for $\mathrm{KW}$ and collaboration in a global context, especially for SERVICE and PERFORM, who reported a good ICT infrastructure in the Nordic country. We observed that the difference of ICT tools provided in each location could hinder communication (i.e., DESIGN and PROTO teams). DESIGN and PERFORM teams worked for the same company and in the same business unit, however, their access of ICT tools and standards at the local sites was different. PERFORM was very positive about their communication tools, and one manager said: "We have excellent equipment and facilities, and all our tools work fine!" While in DESIGN we observed problems with sharing designs and digital data with remote groups and problems with videoconference tools outside the firewalls (e.g., when somebody was working late at night in the Nordic site at home and communicated with the US site in 
their office). A manager of DESIGN mentioned: "There is no practical tool for sharing the data, prototypes, pictures or working collaboratively."

SERVICE and PROTO teams worked for the same global company, but a different business unit, and had different ICT standards and infrastructures in their local sites. SERVICE had a high quality for ICT usage for communication and had company mobile phones, they had mainly problems with limited access to meeting rooms with remote connections. PROTO team members on the other hand used their own personal mobile phones (which were not reimbursed by the company). They reported many difficulties collaborating with remote team members and partners due to lack of tools for communication and limited access to high quality video conferencing rooms. PROTO and DESIGN teams reported that the dated ICT tools provided by the company on the local sites were perceived as a major hindrance for distributed collaboration. The lack of ICT tools and standards complicated the transfer of information and knowledge.

Social workplace. The social workplace supports the interaction between people, it is embedded in the physical and virtual workplace, and shows the importance of informal working areas, coffee corners and proximity to colleagues for ad-hoc and informal interactions. The teams reported that the proximity to their team was very important and one of the main reasons for coming or traveling to the office. In all teams the informal places are used for ad hoc discussions and social gatherings. In SERVICE the informal spaces were used often daily for both informal and formal meetings. In PROTO we observed that due to cost reductions the informal coffee corner was taken away, and many members mentioned that this had a negative impact on their motivation and informal community building. The remote members (especially the isolated members) however mentioned the difficulty of not having a social environment to meet each other informally and they felt they were left out. 


\section{Organization context requires policy and infrastructure alignment}

The organization context is represented by organization culture, policies and standards, i.e., the organizational context in which the teams are working. Due to the global economical situation, the global high-tech companies were implementing organizational changes and cost reductions during the research period. From the interviews and surveys, all cases reported their current challenges on company policies related to distributed $\mathrm{KW}$, such as the lack of company alignment of location workplace and ICT infrastructure policies. The teams faced cost savings on ICT, reduction of travel budget and workspace, which were perceived as frustrating and counterproductive. A manager from the SERVICE case mentioned: "One common policy across the whole company is moving more towards virtual and global teams, but the company does not give you the framework all the time to do your work... the company pushes you in that direction to do your work like that [virtual and global work], but it does not support you in terms of policies, in terms of giving you the freedom, in terms of giving the tools to do it."

All companies cut travel budgets and workspace, e.g., in PROTO reduced the number and space of labs, in SERVICE and PERFORM the desk space was reduced, and DESIGN worked in a workplace that did not support their work. Furthermore, the ICT infrastructure policy of the company impacted remote communication and collaboration, especially while traveling or working mobile since they need to be in constant contact with their team. PROTO and DESIGN were impacted by local ICT policies on security, lack of standardization, and accessibility, which hindered remote collaboration. The US DESIGN manager mentioned: "The firewalls firm restricted policy is a hindrance for working in our team. The policies of the organizations were perceived as a hindrance by $15 \%$ of the PROTO teams in the background survey. 


\section{Discussion}

These findings emphasize the fact that contexts for distributed KW change and differ due to geographical distribution, mobility, and multiple locations used to perform knowledge work. Contexts are changing in two meanings. First, activities of a team take place in different locations, i.e., DESIGN team with three remote locations. Second, team members move and travel a lot being mobile and multi-locational using many locations to work, i.e., SERVICE and the PROTO teams. Consequently knowledge workers, teams, and organizations need to constantly adapt, readjust, and align to the changing work contexts.

Many researchers mention the difficulty in studying KW performance and productivity (Antikainen \& Lönnqvist, 2005; Bosch-Sijtsema et al., 2009; Davenport et al., 1996; Orlikowski, 2000; Pyöriä, 2005) as well as the difficulty to find suitable categories and methods to study KW (Ramírez \& Nembhard, 2004). Therefore, we argue that traditional productivity measures of $\mathrm{KW}$ based on output per input need to be extended with factors concerning the context of KW to include workplace, organization policy, and organization infrastructure. From the findings it becomes clear that $\mathrm{KW}$ is impacted by the context in which knowledge workers perform their activities. This context is different for distributed team members and the context is changing when team members travel, work mobile, and work in multiple locations. Geographically distributed work requires an alignment at the organizational level in terms of workplace, organization policy, and ICT infrastructure needed for KW teams to collaborate. For mobile knowledge work - due to working in different locations people have to travel between sites - teams and its members need to adapt and readjust to the local context, i.e., the social and physical workplace, organization policy and local ICT infrastructure. The new ways of working in terms of global, mobile, and multilocational knowledge work requires knowledge workers and teams to readjust and adapt to 
the different contexts, and an alignment of the organization policy and infrastructure at the organization level.

In VT literature, team performance as well as team tasks, structure, and processes impact team outcomes. Kozlowski and Ilgen (2006) argue that a team is embedded in multilevel systems with individual, team and organizational levels. Therefore, the context in terms of workplace including physical, virtual and social spaces in which the team works, and organization policy and infrastructure that supports it, need to be included. In VT literature the focus has been on culture, conflict, trust (Hertel et al., 2005; Jarvenpaa \& Leidner, 1999; Martins et al., 2004) and technology supporting VT communication and collaboration. However, VT literature has overlooked the importance of changing physical environments and the alignment needed within the organization context in which VT members work and which affects their work through IT infrastructure, policies and organizational culture. Furthermore, traditional KW productivity methods have mainly focused on individual KWP (Ramírez \& Nembhard, 2004) and have neglected KWP in teams, either collocated or virtual. KWP literature often focussed on the output/input formulae and has neglected distributed team work processes that impact outputs. Even though distributed collaboration often takes place in multiple locations, virtual team performance literature neglects to discuss the topic of multiple locations or the impact of changing workplaces of knowledge workers (Cairns, 2002; Halford, 2008; Vartiainen \& Hyrkkänen, 2010) in terms of the physical place where the VT member works - which can be anywhere; the virtual place in which the VT member collaborates and communicates is often discussed in IT related literature, but goes hand in hand with the physical and social place in which VT members operate.

By extending traditional KWP methods with context factors like workplace and organization policy and infrastructure, we found specific challenges for distributed $\mathrm{KW}$ in new working contexts. Below we discuss the main challenges that were found to impact 
distributed KW.

Asymmetry of team configuration: New ways of working creates contexts that are different and that are changing. The changing and distributed context has an impact on how teams cooperate and how teams are configured. From the eight teams we found that an asymmetry in team configuration (O'Leary \& Cummings, 2007), diversity and disparity in skills, knowledge, abilities and experience for distributed teams can have a negative impact on work processes, knowledge transfer, collaboration, and increases task ambiguity. The asymmetry in our cases in terms of seniority and experience had an important impact on the distributed team's performance (e.g., DESIGN) in how they worked together remotely. The team structure is often discussed to have an impact on team effectiveness (Antoni \& Hertel, 2009; Cohen \& Bailey, 1997; Gladstein, 1984; Guzzo \& Dickson, 1996) and VT performance (e.g., Armstrong \& Cole, 2002; Cramton, 2001; Hertel et al., 2005; Maznevski \& Chudoba, 2000). According to Peters and Karren (2009), team members value the expected contribution of VT skills diversity and relate this to performance. According to Hertel et al. (2005) restricted communication opportunities - due to time differences - in VTs might prevent a constructive use of diversity and can increase misunderstandings and conflict. However, a balanced mixture of team configuration diversity, seniority and experienced people who are collocated can have beneficial impacts on the team work processes, and team satisfaction, as seen from this study.

Lack of time and access to resources: The changing and distributed context of $\mathrm{KW}$ in new work settings had an important impact on the work processes of the distributed teams (Fruchter, Bosch-Sijtsema, \& Ruohomäki, 2010). From the case studies we found that teams and their members needed to adapt and readjust their way of working when changing their context in terms of workplace. For example the mobile case of SERVICE showed that team members who travel to the Nordic location needed to navigate and find their team members 
and adjust to the local physical and social workplace. All teams faced a high workload, high information loads, worked in multiple teams, and had multiple tasks. Furthermore, the teams and their members worked in multiple workplaces for their tasks and project teams (i.e., different sites, and/or different locations locally like labs, model workshops, meeting rooms, team rooms, dedicated desks). This implies that project team members have to switch from one project team to another and from one task to another. Switching between projects, tasks and different and changing contexts contribute to a high attention load increasing in this way cognitive and affective mental workload. In addition, work schedules do not take into consideration the time required for knowledge workers to switch mentally from one project to another. Consequently, knowledge workers have little reflection time. From KW literature the reflection time is an important aspect in order to learn and transfer knowledge and impacts KW productivity (Davenport, et al., 2002). The lack of reflection time in combination with high work and information loads often hinders how knowledge workers are able to deal with highly complex and ambiguous tasks in a distributed and changing context. Distributed settings in our study faced a high task ambiguity and complexity. Because of the geographical distribution tasks take longer time, and scarce face-to-face encounters make it difficult to coordinate the distributed work (Bell \& Kozlowski, 2002; Maznevski \& Chudoba, 2000; Thompson, 1967). The high task complexity triggers a high demand on attention distribution and need for reflection time to deal with this complexity causing losses in work processes. Research on VTs has discussed the importance of planning, i.e., goal setting, communication and coordination as well as interpersonal processes like trust, cohesion and conflict resolution (Armstrong \& Cole, 2002; Hertel et al., 2005; Martins et al., 2004), however, often lacks discussions on the access to resources and time availability.

Impact of the physical, virtual, and social workplace: the workplace is known to have an impact on the work that is performed (Heerwagen et al., 2004), however, the workplace as 
changing context is neglected in KW productivity literature as well as VT literature. The workplace context for distributed teams is different due to geographical distribution and the workplace is changing due to mobile and multi-locational work. The workplace has an impact on KW since knowledge workers need to adjust and adapt to different workplaces as well as to changing workplaces (physical, virtual and social).

Furthermore, we found that tasks are performed in different locations and places. In our cases tasks were performed in different places like the dedicated desks, meeting rooms, video conference rooms, labs and workshops as well as in various locations during traveling, different sites or at home. Due to the changing work context and workplace, geographical distribution and mobility knowledge workers move from one space to another, from their dedicated desk or office to a meeting room that is an ICT augmented place, to a free address desk. Knowledge workers are mobile in their corporate campus, which implies that they have to adjust and adapt to new places constantly. Furthermore, the fact that knowledge workers are on the move makes it more difficult to find or locate people (i.e., SERVICE case study). The constant adjustment and adaptation to the place is not only related to the physical and virtual workplace, but also to the social workplace. The social and informal contact between team members is important for team satisfaction, work climate, and is positively related to virtual team performance (Davenport et al., 2002; Hertel et al., 2005; Scott, 2005). However, due to mobility, multi-locational work, changing contexts and geographical distribution, team members have less opportunity to easily locate each other and meet informally.

Next to the difficulties of adapting and adjusting to new places, the workplace needs to support the tasks performed by distributed teams. In order to support $\mathrm{KW}$, some of the cases companies adjusted the workplace to become suitable for the specific tasks performed by a distributed team and provided a choice of workplaces for KW. The choice of flexible workplaces that support the type of task that is performed helps the knowledge worker to be 
more effective. The Nordic cases (SERVICE and PERFORM) provided a variety of workplaces, both for individual and collaborative tasks. This was perceived as an enabler of KW. However, not all workplaces supported the remote or creative work (e.g., in DESIGN and all five PROTO teams). This had negative implications for sharing knowledge, collaboration, and communication. A workplace that supports remote work can enable engagement, interaction, sharing knowledge and create visibility and awareness of remote and local conditions. The intersection of the design of physical workplaces, the rich electronic content such as video, audio, sketching, and ways people interact and collaborate are important in supporting KW (Fruchter, 2005). Depending on the task complexity, interdependency and ambiguity as well as the content of the collaborative or individual task, team members should have the ability to choose from a set of workplaces for their physical, virtual as well as their social work environment. For distributed collaboration, the social workplaces are very important for interaction, knowledge transfer, and collaboration (Davenport et al., 2002). Working remotely lowers the frequency of informal knowledge transfer and therefore workplaces can support the informal interaction that can also help to disambiguate tasks driven by location or culture. Non-job-related communication contents are related to performance and members' satisfaction of global business teams and to their climate (Hertel et al., 2005). We emphasize that team configuration structure as well as type of task and complexity needs to be supported by workplace choices and organization policies and standards. However, from our data we also found that too much workplace choice and flexibility in combination with a strict and rigid workplace policy (e.g., SERVICE) can hinder KW.

Organization context providing aligned workplace policies and ICT infrastructure standards increases the ability to collaborate distributed. The importance of organization context for team performance is confirmed in literature (Antoni \& Hertel, 2009; Cohen \& 
Bailey, 1997). However, few discussions focus on the impact of workplace and IT infrastructure on distributed KW (Hertel et al., 2005). The eight studied cases showed that the organization context in terms of ICT infrastructure and workplace policy can be an enabler as perceived in the Nordic case of PERFORM - or hindrance for KW - as perceived in the five teams of PROTO and in DESIGN. The workplace as well as the organization context could support distributed collaboration in terms of offering flexible workplaces for remote work, sharing knowledge and information, as well as supporting remote teams with suitable ICT standards and infrastructures on all locations, so that team members are able to share not only text, but also pictures, prototypes, blue-prints and ideas more easily with each other. An important question in studying distributed $\mathrm{KW}$ in new working contexts is if and how company policies support distributed, mobile, and multi-locational knowledge work.

\section{Conclusions}

In conclusion, we can state that the work context for distributed KW has a major impact on KW performance and productivity. The changing and geographically distributed work context of knowledge workers in new work settings impact how distributed teams deal with complex tasks, asymmetric team configurations, high workloads and lack of reflection time. They are typically challenged to constantly adapt and adjust to changing work places, and require alignment of organization policies and infrastructures.

This paper proposes a framework to study $\mathrm{KW}$ of distributed teams in new working contexts in terms of performance and productivity. The framework presents factors concerning the context in which distributed knowledge workers operate. The framework focuses on five key factors that impose challenges on $\mathrm{KW}$ in new working contexts, i.e., task, team structure, work process, workplace, and organization context. We illustrate the use of the framework in eight cases of distributed teams and focus in particularly on specific 
challenges within these five factors that impact the performance of $\mathrm{KW}$ in new working settings of distributed, mobile and multi-locational work. The framework provides both theoretical and practical benefits. From a theoretical point of the view, the framework can be applied to study KW in new work contexts. From a practical point of view it explicitly emphasises the importance of strategic alignment and integration of the different corporate business units that are responsible for task, team structure, process, workplace and organizational infrastructure and policy, which currently act as independent business units.

Furthermore, topics such as culture, trust building, and technology in distributed collaboration as well as the social workplace are important topics for future research. The analysis framework for $\mathrm{KW}$ that integrates the five factors - team task, team structure, team work process, workplace, and organization context - provides opportunities for future research to extend the characteristics of any of these five factors and their interplay to contribute further insights into KW in new work contexts of distributed collaboration.

Acknowledgements: This study is part of the joint Stanford-Aalto University School of Science research project ProWork: Workplace Management that is sponsored by the Finnish Funding Agency for Technology and Innovation (TEKES), ProWork project company partners, and the PBL Lab at Stanford University.

\section{References}

Andriessen, J. H. E. (2003). Working with groupware. Understanding and evaluating collaboration technology. London: Springer.

Antikainen, R., \& Lönnqvist, A. (2005). Knowledge worker productivity assessment. Proceedings of the 3rd Conference on Performance Measurement and Management, Nice, France, September 2005. 
Antoni, C., \& Hertel, G. (2009). Team processes, their antecedents and consequences: Implications for different types of teamwork. European Journal of Work and Organizational Psychology, 18, 253-266.

Armstrong, D. J., \& Cole, P. (2002). Managing distances and differences in geographically distributed work groups. In P. J. Hinds \& S. Kiesler (Eds.), Distributed work (pp. 167-186). Cambridge, MA: MIT Press.

Becker, F. (2002). Improving organisational performance by exploiting workplace flexibility. Journal of Facilities Management, 1, 154-162.

Baruch, Y. (1997). High technology organization - what it is, what it isn't. International Journal of Technology Management, 13, 179-195.

Baruch, Y. \& Holtom, B. (2008). Survey response rate levels and trends in organizational research. Human Relations, 61, 1139-1160.

Bell, B. S., \& Kozlowski, S. W. J. (2002). A typology of virtual teams. Implications for effective leadership. Group and Organization Management, 27, 14-49

Bosch-Sijtsema, P., Ruohomäki, V., \& Vartiainen, M. (2009). Knowledge work productivity in distributed teams. Journal of Knowledge Management, 13, 533-546.

Bosch-Sijtsema, P. (2007). The impact of individual expectations and expectation conflicts on virtual teams. Group \& Organization Management, 32, 358-388.

Cairns, G. (2002). Aesthetics, morality and power: design as espoused freedom and implicit control. Human Relations, 55, 799-820.

Chan, J. K., Beckman, S. L. \& Lawrence, P. G. (2007). Workplace design. A new managerial 50 imperative. California Management Review, 49, 6-22.

Chi, N-W., Huang, Y-M. \& Lin, S-C. (2009). A Double-Edged sword? Exploring the curvilinear relationship between organizational tenure diversity and team innovation: The moderating role of team-oriented HR practices. Group \& Organization Management, 34, 
698-726.

Cohen, S. G., \& Bailey, D. E. (1997). What makes teams work: group effectiveness research from the shop floor to the executive suite source. Journal of Management, 23, 239-290.

Corbin, J. \& Strauss, A. (2008). Basics of qualitative research: 3rd Ed. Thousand Oaks: Sage.

Cramton, D. C. (2001). The mutual knowledge problem and its consequences for dispersed collaboration. Organization Science, 12, 346-371.

Davenport, T. H., \& Prusak, L. (1995). Working knowledge. How organizations manage what they know. Harvard Business School Press: Boston.

Davenport, T. H., Jarvenpaa, S. L., \& Beers, M. C. (1996). Improving knowledge work processes. Sloan Management Review, 37, 53-65.

Davenport, T. H., Thomas, R. J., \& Cantrell, S. (2002). The mysterious art and science of knowledge worker productivity. MIT Sloan Management Review, 44, 23-29.

Drucker, P. F. (1991). The new productivity challenge. Harvard Business Review, November - December, 69, 69-79.

Drucker, P. F. (1999). Knowledge-worker productivity. The biggest challenge. California Management Review, 41, 79-94.

Eisenhardt, K. M. (1989). Building theories from case study research. Academy of Management Review, 14, 532-550.

Fruchter, R. (2005). Degrees of engagement in interactive workspaces. International Journal of AI and Society, 19, 8-21.

Fruchter, R., Bosch-Sijtsema, P.M. \& Ruohomäki, V. (2010). Tension between perceived collocation and actual geographical distribution in project teams. International Journal of AI \& Society, 25, 183 192.

Gareis, K., Lilischkis, S. \& Mentrup, A. (2006). Mapping the mobile ework force in Europe. 
In: J. H. E. Andriessen \& M. Vartiainen (Eds.), Mobile Virtual Work-A New Paradigm? (pp. 45-69). Heidelberg: Springer.

Gladstein, D. L. (1984). Groups in Context: A model of task group effectiveness. Administrative Science Quarterly, 29, 499-517.

Guzzo, R. A. \& Dickson, M. W. (1996). Teams in organizations: recent research on performance and effectiveness. Annual Review of Psychology, 47, 307-38.

Hackman, J. R. (1987). The design of work teams. In J. L. Lorsch (Ed.), Handbook of Organizational Behavior (pp. 315-342). Englewood Cliffs, NJ: Prentice Hall.

Halford, S. (2008). Sociologies of space, work and organization: from fragments to spatial theory. Sociology Compass, 2, 925-943.

Han, T. W. \& Williams, K. J. (2008). Multilevel investigation of adaptive performance: individual- and team-level relationships. Group \& Organization Management, 33, 657-684.

Harrison, A., Wheeler, P., \& Whitehead, C. (2004). The distributed Workplace. London: Routledge.

Heerwagen, J. H., Kampschroer, K., Powell, K. M., \& Loftness, V. (2004). Collaborative knowledge work environments. Building Research \& Information, 32, 510-528.

Hertel, G., Geister, S., \& Konradt, U. (2005). Managing virtual teams: A review of current empirical research. Human Resource Management Review, 15, 69-95.

Jarvenpaa, S. L., \& Leidner, D. E. (1999). Communication and trust in global virtual teams. Organization Science, 10, 791-815.

Kozlowski, S. W. J., \& Ilgen, D. R. (2006). Enhancing the effectiveness of work groups and teams. Psychological Science in the Public Interest, 7, 77-124.

Lin, C-P. (2010). Learning task effectiveness and social interdependence through the mediating mechanisms of sharing and helping: A survey of online knowledge workers. Group \& Organization Management, 35, 299-328. 
Marks, M. A., Mathieu, J. E., \& Zaccaro, S. J. (2001). A temporally based framework and taxonomy of team processes. Academy of Management Review, 26, 356-376.

Martins, L. L., Gilson, L. L., \& Maynard, M. T. (2004). Virtual teams: What do we know and where do we go from here? Journal of Management, 30, 805-835.

Maznevski, M. L., \& Chudoba, K. M. (2000). Bridging space over time: global virtual team dynamics and effectiveness. Organization Science, 11, 473-492.

McDonald, S. (2005). Studying actions in context: a qualitative shadowing method for organizational research. Qualitative Research, 5, 455-473.

Moon, T. (2010). Organizational cultural intelligence: dynamic capability perspective. Group \& Organization Management, 35, 456-493.

O'Leary, M. B., \& Cummings, J. N. (2007). The spatial, temporal, and configurational characteristics of geographic dispersion in teams. MIS Quarterly, 31, 433-452.

Orlikowski, W. J. (2000). Knowing in practice: Enacting a collective capability in distributed organizing. Organization Science, 13, 249-273.

Peters, L. \& Karren, R. J. (2009). An examination of the roles of trust and functional diversity on virtual team performance ratings. Group \& Organization Management, 34, 479504.

Pyöriä, P. (2005). The concept of knowledge work revisited. Journal of Knowledge Management, 9, 116-127.

Ramírez, Y. W., \& Nembhard, D. A. (2004). Measuring knowledge worker productivity: A taxonomy. Journal of Intellectual Capital, 5, 602-928.

Richert, E. \& Rush, D. (2005). How new infrastructure provided flexibility, controlled cost and empowered workers at SUN Microsystems. Journal of Corporate Real Estate, 7, 271279.

Rousseau, V. \& Aubé, C. (2010). Team self-managing behaviors and team effectiveness: the 
moderating effect of task routineness. Group and Organization Management, 35, 751-781.

Schultze, U. (2000). A confessional account of an ethnography about knowledge work. MIS Quarterly, 24, 3-41.

Scott P. B. (2005). Knowledge workers: social, task and semantic network analysis. Corporate Communications: An International Journal, 10, 257-277.

Taylor, S. \& Spicer, A. (2007). Time for space: A narrative review of research on organizational spaces. International Journal of Management Reviews, 9, 325-346.

Thompson, J. D. (1967). Organizations in action: Social Science Bases of Administrative Theory. US: McGraw Hill.

Vartiainen, M. \& Hyrkkänen, U. (2010). Changing requirements and mental workload factors in mobile multi-locational work. New Technology, Work and Employment, 25, 117-135.

Vischer. J.C. (2005). Space meets status: designing workplace performance. New York: Routledge. 
Figure 1: Factors impacting knowledge work in distributed collaboration.

\section{ORGANIZATION CONTEXT:}

Policy, ICT standard infrastructure, Culture

\section{WORKPLACE:}

Physical, virtual (ICT), and social workplace

TEAM WORK PROCESSES:

Work load, information load, attention distribution, reflection time, communication, collaboration, planning and action process

\section{TEAM STRUCTURE}

Experience, skills and knowledge, geo distribution, subgrouping

TEAM TASK: complexity, ambiguity, interdependence

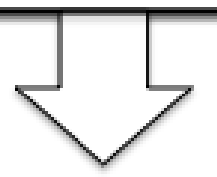

KNOWLEDGE WORK PERFORMANCE \& PRODUCTIVITY 
Table 1: Case study team characteristics

\begin{tabular}{|c|c|c|c|c|}
\hline Teams & Type of work & Distance, configuration, and task & Communication Mode & Workplace \\
\hline $\begin{array}{l}\text { SERVICE } \\
\text { (Nordic) } \\
(\mathrm{N}=8)\end{array}$ & $\begin{array}{l}\text { Customer } \\
\text { relation } \\
\text { management } \\
\text { (customers in } \\
\text { Asia, EU, } \\
\text { US) }\end{array}$ & $\begin{array}{l}\text { Spatial: EU team pan European multi- } \\
\text { culture. Team consists of senior managers } \\
\text { managing customer relations in different } \\
\text { EU countries. } \\
\text { Configuration: Five sites; remote managers } \\
\text { ( } \mathrm{n}=4 \text { ) travel once per month to Nordic } \\
\text { headquarter location. Rest of manager } \\
\text { group ( } \mathrm{n}=4 \text { ) collocated in Nordic head } \\
\text { quarter office (asymmetry). } \\
\text { Task: Meetings with customers, problem } \\
\text { solving and negotiations. }\end{array}$ & $\begin{array}{l}\text { Face-to-face: } 20 \% \\
\text { Synchronous: } 40 \% \\
\text { Asynchronous: } 40 \%\end{array}$ & $\begin{array}{l}\text { Open office } \\
\text { with free } \\
\text { address and } \\
\text { dedicated desks. } \\
\text { Remote } \\
\text { managers work } \\
\text { from home, } \\
\text { when they are } \\
\text { not at HQ or } \\
\text { customer site. }\end{array}$ \\
\hline $\begin{array}{l}\text { PROTO } \\
\text { MANAGE } \\
(\mathrm{US})(\mathrm{N}=8)\end{array}$ & $\begin{array}{l}\text { Prototyping } \\
\text { Management } \\
\text { team }\end{array}$ & $\begin{array}{l}\text { Spatial: Multi-disciplinary management } \\
\text { team - US based ( } \mathrm{n}=8 \text { ), with a factory in } \\
\text { Asia (time zone difference). } \\
\text { Configuration: different sites ( } \mathrm{n}=3 \text { ), one } \\
\text { isolated remote manager (asymmetry). } \\
\text { Task: Management of different multi- } \\
\text { disciplinary groups. Managers from US } \\
\text { and Asia dealing weekly with } \\
\text { manufacturing issues at the factory in Asia. }\end{array}$ & $\begin{array}{l}\text { Face-to-face: } 34 \% \\
\text { Synchronous: } 28 \% \\
\text { Asynchronous: } 38 \%\end{array}$ & $\begin{array}{l}\text { Cubicles with } \\
\text { dedicated desks } \\
\text { and prototyping } \\
\text { labs. }\end{array}$ \\
\hline $\begin{array}{l}\text { PROTO } \\
\text { ENGINEER } \\
1(\mathrm{US})(\mathrm{N}= \\
9)\end{array}$ & $\begin{array}{l}\text { Development } \\
\text { of prototypes } \\
\text { of large } \\
\text { machines }\end{array}$ & $\begin{array}{l}\text { Spatial: Collocated US team of nine } \\
\text { engineers, dealing with factory in Asia } \\
\text { (time difference). } \\
\text { Configuration: Multiple cultures and } \\
\text { engineering disciplines. } \\
\text { Task: Developing and creating prototypes } \\
\text { for large machines. Multiple cultures and } \\
\text { engineering disciplines. }\end{array}$ & $\begin{array}{l}\text { Face-to-face: } 50 \% \\
\text { Synchronous: } 20 \% \\
\text { Asynchronous: } 30 \%\end{array}$ & $\begin{array}{l}\text { Cubicles with } \\
\text { dedicated desks, } \\
\text { testing and } \\
\text { prototype labs } \\
\text { in between } \\
\text { cubes. }\end{array}$ \\
\hline PROTO & Development & Spatial: Engineering team $(n=13)$ both & Face-to-face: $54 \%$ & Cubicles with \\
\hline
\end{tabular}




\begin{tabular}{|c|c|c|c|c|}
\hline $\begin{array}{l}\text { ENGINEER } \\
2 \text { (US) } \\
(\mathrm{N}=13)\end{array}$ & $\begin{array}{l}\text { of prototypes } \\
\text { of large } \\
\text { machines }\end{array}$ & $\begin{array}{l}\text { collocated and remote in US (time } \\
\text { difference), dealing with factory in Asia } \\
\text { (time difference). } \\
\text { Configuration: Several team members } \\
\text { isolated remotely. Multiple cultures and } \\
\text { engineering disciplines (asymmetry). } \\
\text { Task: Developing and creating prototypes } \\
\text { for large machines. }\end{array}$ & $\begin{array}{l}\text { Synchronous: } 16 \% \\
\text { Asynchronous: } 30 \%\end{array}$ & $\begin{array}{l}\text { dedicated desks, } \\
\text { testing and } \\
\text { prototype labs } \\
\text { in between } \\
\text { cubes. }\end{array}$ \\
\hline $\begin{array}{l}\text { PROTO } \\
\text { PROCURE } \\
(\mathrm{US})(\mathrm{N}=12)\end{array}$ & $\begin{array}{l}\text { Procurement } \\
\text { for the } \\
\text { prototyping } \\
\text { team }\end{array}$ & $\begin{array}{l}\text { Spatial: Collocated team }(\mathrm{n}=12), \text { working } \\
\text { daily with Asia, US and EU (time } \\
\text { difference). } \\
\text { Configuration: Multi-cultural team. } \\
\text { Task: Dealing with global suppliers. }\end{array}$ & $\begin{array}{l}\text { Face-to-face: } 36 \% \\
\text { Synchronous: } 23 \% \\
\text { Asynchronous: } 41 \%\end{array}$ & $\begin{array}{l}\text { Cubicles with } \\
\text { dedicated desks. }\end{array}$ \\
\hline $\begin{array}{l}\text { PROTO } \\
\text { TECH (US) } \\
(\mathrm{N}=10)\end{array}$ & $\begin{array}{l}\text { Technical } \\
\text { team } \\
\text { building and } \\
\text { testing } \\
\text { prototypes }\end{array}$ & $\begin{array}{l}\text { Spatial: US team of collocated engineers } \\
\text { (n=10), who work in different locations, } \\
\text { and work with factory in Asia (time } \\
\text { difference). } \\
\text { Configuration: Multi-cultural team. } \\
\text { Task: Testing and building prototypes. } \\
\text { Close cooperation with developers. } \\
\text { Problem solving and building of prototypes } \\
\text { in US and Asia (factory). }\end{array}$ & $\begin{array}{l}\text { Face-to-face: } 46 \% \\
\text { Synchronous: } 18 \% \\
\text { Asynchronous: } 36 \%\end{array}$ & $\begin{array}{l}\text { Cubicles with } \\
\text { dedicated desks, } \\
\text { testing and } \\
\text { prototype labs } \\
\text { in between } \\
\text { cubes. }\end{array}$ \\
\hline $\begin{array}{l}\text { DESIGN } \\
\text { (Global) } \\
(\mathrm{N}=15)\end{array}$ & $\begin{array}{l}\text { Design and } \\
\text { rapid } \\
\text { prototyping } \\
\text { of high tech } \\
\text { small devices }\end{array}$ & $\begin{array}{l}\text { Spatial: Distributed team in US ( } \mathrm{n}=10) \text {, } \\
\text { EU }(\mathrm{n}=4) \text {, Japan }(\mathrm{n}=1) \text { (time difference). } \\
\text { Configuration: Multi-disciplinary and } \\
\text { multi-cultural design team (EU, US, Asia). } \\
\text { One isolated member and asymmetry in } \\
\text { team configuration. } \\
\text { Task: Creating, analyzing, developing and } \\
\text { building prototypes and ideas. }\end{array}$ & $\begin{array}{l}\text { Face-to-face: } 54 \% \\
\text { Synchronous: } 17 \% \\
\text { Asynchronous: } 29 \%\end{array}$ & $\begin{array}{l}\text { Open office } \\
\text { with dedicated } \\
\text { desks. } \\
\text { Prototype labs } \\
\text { remote. }\end{array}$ \\
\hline $\begin{array}{l}\text { PERFORM } \\
\text { (Nordic) }\end{array}$ & $\begin{array}{l}\text { Performance } \\
\text { management }\end{array}$ & $\begin{array}{l}\text { Spatial: } \text { Collocated } \text { EU team }(\mathrm{n}=8) \\
\text { managing } 50 \text { people in EU, Asia and US }\end{array}$ & $\begin{array}{l}\text { Face-to-face: } 30 \% \\
\text { Synchronous: } 30 \%\end{array}$ & $\begin{array}{l}\text { Open plan } \\
\text { office with }\end{array}$ \\
\hline
\end{tabular}




\begin{tabular}{|c|c|c|c|c|}
\hline$(\mathrm{N}=8)$ & team & $\begin{array}{l}\text { (time difference). } \\
\text { Configuration: Multi-cultural team (EU, } \\
\text { Asia). } \\
\text { Task: Part of the design department for } \\
\text { performance management of designs and } \\
\text { design teams. }\end{array}$ & Asynchronous: $40 \%$ & $\begin{array}{l}\text { dedicated desks, } \\
\text { and team } \\
\text { rooms. }\end{array}$ \\
\hline
\end{tabular}


Table 2: Summary of data collection in eight cases. $(\mathrm{N}=$ total number of people studied per case)

\begin{tabular}{|c|c|c|c|c|}
\hline Cases & $\begin{array}{l}\text { Survey response } \\
\text { rate }(\%, \mathrm{n})\end{array}$ & $\begin{array}{l}\text { Interviews } \\
\text { (n) }\end{array}$ & $\begin{array}{l}\text { Observations: workplace and } \\
\text { meetings }\end{array}$ & $\begin{array}{l}\text { Observation } \\
\text { of teams (n, } \\
\text { hours) }\end{array}$ \\
\hline $\begin{array}{l}\text { SERVICE } \\
(\mathrm{N}=8)\end{array}$ & $\begin{array}{l}\text { S1: } 100 \%(8) \\
\text { S2: } 88 \%(7) \\
\text { S3: } 88 \%(7)\end{array}$ & 10 & $\begin{array}{l}\text { - 2-day observation (16h) } \\
\text { - } 1 \text { discussion meeting with } \\
\text { whole team }(1 \mathrm{~h})\end{array}$ & $\begin{array}{l}4 \text { Persons } \\
(32 \mathrm{~h})\end{array}$ \\
\hline $\begin{array}{l}\text { PROTO } \\
\text { MANAGE } \\
(\mathrm{N}=8)\end{array}$ & $\begin{array}{l}\text { S1: } 100 \%(8) \\
\text { S2: } 100 \%(8) \\
\text { S3: } 75 \%(6)\end{array}$ & 4 & $\begin{array}{l}\text { - 2-day observation (16h) } \\
-1 \text { face-to-face meeting } \\
\text { observed ( } 3 \mathrm{~h}) \\
-2 \text { teleconference meetings } \\
\text { US-Asia observed (4h) } \\
\text { - } 4 \text { discussion meetings with } \\
\text { whole team }(3.5 \mathrm{~h})\end{array}$ & 1 person $(4 h)$ \\
\hline $\begin{array}{l}\text { PROTO } \\
\text { ENGINEER } 1 \\
(\mathrm{~N}=9)\end{array}$ & $\begin{array}{l}\text { S1: } 89 \%(8) \\
\text { S2: } 78 \%(7) \\
\text { S3: } 78 \%(7)\end{array}$ & 2 & - 2-day observation (16h) & $\begin{array}{l}2 \text { persons } \\
(8 \mathrm{~h})\end{array}$ \\
\hline $\begin{array}{l}\text { PROTO } \\
\text { ENGINEER } 2 \\
(\mathrm{~N}=13)\end{array}$ & $\begin{array}{l}\text { S1: } 92 \%(12) \\
\text { S2: } 85 \%(11) \\
\text { S3: } 100 \%(13)\end{array}$ & 1 & $\begin{array}{l}\text { - 2-day observation }(16 \mathrm{~h}) \\
\text { - Face-to-face team meeting } \\
\text { (1h) }\end{array}$ & 1 person $(4 h)$ \\
\hline $\begin{array}{l}\text { PROTO } \\
\text { PROCURE } \\
(\mathrm{N}=12)\end{array}$ & $\begin{array}{l}\text { S1: } 92 \%(11) \\
\text { S2: } 92 \%(11) \\
\text { S3: } 67 \%(8)\end{array}$ & 2 & - 2-day observation (16h) & 1 person $(4 h)$ \\
\hline $\begin{array}{l}\text { PROTO } \\
\text { TECH }(\mathrm{N}=10)\end{array}$ & $\begin{array}{l}\text { S1: } 100 \%(10) \\
\text { S2: } 80 \%(8) \\
\text { S3: } 90 \%(9)\end{array}$ & 2 & - 2-day observation (16h) & 1 person $(4 h)$ \\
\hline $\begin{array}{l}\text { DESIGN }(N= \\
15)\end{array}$ & $\begin{array}{l}\text { S1: } 100 \%(15) \\
\text { S2: } 93 \%(14) \\
\text { S3: } 68 \%(10)\end{array}$ & 6 & $\begin{array}{l}\text { - 2-day observation (16h) } \\
\text { - } 5 \text { Ad hoc face-to-face } \\
\text { meetings (30min-3h) } \\
\text { - } 1 \text { teleconference meeting } \\
\text { US site with Nordic EU (1h) }\end{array}$ & $\begin{array}{l}8 \text { Persons } \\
\text { (whole US } \\
\text { team) }(16 \mathrm{~h})\end{array}$ \\
\hline $\begin{array}{l}\text { PERFORM } \\
(\mathrm{N}=8)\end{array}$ & $\begin{array}{l}\text { S1: } 100 \%(8) \\
\text { S2: } 75 \%(6) \\
\text { S3: } 75 \%(6)\end{array}$ & 8 & $\begin{array}{l}\text { - 2-day observation Nordic } \\
(16 \mathrm{~h}) \\
-1 \text { discussion meeting with } \\
\text { whole team }(1 \mathrm{~h})\end{array}$ & $\begin{array}{l}4 \text { persons } \\
(32 \mathrm{~h})\end{array}$ \\
\hline Total: 8 teams & $\mathrm{N}=83$ & 35 people & & 22 people \\
\hline
\end{tabular}

